\title{
PATHOPHYSIOLOGY
}

\author{
UDC 616.024-002.17
}

\section{Old wine in new wineskins. Hamman-Rich syndrome has much in common with severe COVID-19: Do they share any link of pathogenesis or depend on the similar aetiological factor(s)?*}

\author{
Ya. V.Ivashkevich ${ }^{1}$, A. E. Korovin ${ }^{1}$, A. V. Petyaeva ${ }^{1}$, L. P. Churilov ${ }^{1,2}$ \\ ${ }^{1}$ St. Petersburg State University, \\ 7-9, Universitetskaya nab., St. Petersburg, 199034, Russian Federation \\ 2 St. Petersburg Research Institute of Phthisiopulmonology, Health Ministry of Russia, \\ 2-4, Ligovskiy pr., St. Petersburg, 191036, Russian Federation
}

For citation: Ivashkevich Ya. V., Korovin A.E., Petyaeva A. V., Churilov L.P. Old wine in new wineskins. Hamman-rich syndrome has much in common with severe COVID-19: Do they share any link of pathogenesis or depend on the similar aetiological factor(s)? Vestnik of Saint Petersburg University. Medicine, 2020, vol. 15, issue 2, pp. 93-106. https://doi.org/10.21638/spbu11.2020.201

For the first time the acute interstitial pneumonitis as a main cause of adult idiopathic respiratory distress syndrome was described in 1933-35 by the American medical scholars Louis Virgil Hamman and Arnold Rice Rich as "acute fibrosing alveolitis" later given the eponymous name Hamman-Rich syndrome. This disease targets the interstitium of the lungs and characterized by fulminant onset, acute respiratory disorder with possibility of respiratory failure, being clinically similar to respiratory distress syndrome with the pathomorphologically revealed diffuse alveolar damage. Hamman-Rich syndrome is characterized by rapid progression from symptoms of common cold such as cough, fever, chills and dyspnea to severe respiratory failure. The syndrome affects apparently healthy individuals and is not associated with any anamnestic chronic lung diseases, smoking habits, neither with patients' age or sex. The aetiology and pathogenesis of the Hamman-Rich syndrome are not clear yet. The familiar genetic predisposition is of definite meaning, especially related to mutations of surfactant proteins and their metabolism. The possible mechanistic links of this fulminant lung disease involve: NK-cells, auto-aggressive immune activation and certain types of cytokines during their excessive systemic action, so-called cytokine storm (e.g. interleukin-18 and interleukin-2), which play the leading part in the patho-

* The work is supported by a grant from the Government of the Russian Federation (contract 14.W03.31.0009 of 13.02.2017) for state support of scientific research conducted under the supervision of leading scientists.

(C) Санкт-Петербургский государственный университет, 2020 
genesis of acute lung cell injury resulting in diffuse non-remitting pneumofibrosis. But all these clinical and pathogenetic features are also common for severe COVID-19. Computed tomography is used for instrumental diagnosis of Hamman-Rich syndrome and also gives the lung images quite similar to that of COVID-19, including ground glass opacity symptoms. The authors hypothesize that the same link(s) of pathogenesis underlie the severe course of COVID-19 and Hamman-Rich syndrome. It is possible that cases of Hamman-Rich syndrome were due to the circulation in populations of a less virulent, unrecognized coronavirus, which interacts with the immune system of genetically susceptible individuals in a way similar to SARS-CoV2. For sure, the identification of the characteristics of the genome of patients with Hamman-Rich syndrome will shed light on the genetic mechanisms that predispose to the severe course of COVID-19 and vice versa - the experience of severe COVID-19 treatment can be applied to the therapy of Hamman-Rich syndrome as well.

Keywords: autoimmunity, acute fibrosing alveolitis, acute interstitial pneumonia, COVID-19, Hamman-Rich syndrome, acute respiratory distress syndrome, cytokine storm, complement $\mathrm{C}_{3}$, interleukin-18, macrophages, natural killers, surfactant proteins.

\section{Introduction}

For the first time the atypical respiratory disease caused by SARS-CoV-2 (COVID-19) was diagnosed in Wuhan, People's Republic of China, in December, 2019. The virus is highly contagious. It was noticed that the lung involvement caused by COVID-19 in the elderly people has more severe course compared to the children and adolescents. The problem \#1 in the world is a need in targeted therapy for the acute interstitial pneumonitis and acute respiratory distress syndrome - a dangerous complication of the upper respiratory tract disease triggered by COVID-19 [1]. Severe COVID-19 provokes an inconsistency of anti-viral immune defense, hyperactivation of macrophages, excessive systemic action of inflammatory autacoids, including cytokines (known under imprecise term of "cytokine storm"), systemic endothelial involvement with thrombophilic syndrome and disseminated intravascular coagulation - all together resulting in a variant of shock lung or acute respiratory distress syndrome with fulminant progressing of acute respiratory failure [2]. Also, there are clear evidences for autoimmune links taking part in pathogenesis of severe COVID-19 [3].

But, maybe some aspects of new coronavirus infection COVID-19 have to be interpreted as an old wine in new wineskins?

\section{History of Hamman-Rich syndrome: Different meanings of the same term}

For the first time the acute interstitial pneumonitis as a main cause of idiopathic acute respiratory distress syndrome in adults was described much earlier. In 1933-35 two American medical scholars: an internist Louis Virgil Hamman (1877-1946) and a pathologist Arnold Rice Rich (1893-1968) described an idiopathic syndrome. A bit later in 1944 they detailed the description with few additional cases -4 of them in total (see: Conclusion below). These publications subsequently gave birth to the eponymous name: Hamman-Rich syndrome [4].

The disease targets the interstitium of the lung and is characterized by fulminant onset, sometimes with a prodromal period of few days, with non-specific complaints de- 
rived from acute phase response, later manifested in acute respiratory insufficiency with the possibility of gravid respiratory failure, clinically similar to acute respiratory distress syndrome with diffuse alveolar damage, according to the histopathological results of the biopsies $[5 ; 6]$.

At the beginning the term "Hamman-Rich syndrome" was broadly and incorrectly applied to define all forms of diffuse idiopathic pulmonary fibrosis. The term "acute interstitial pneumonia" was introduced by Katzenstein et al in 1968 to define all of the cases which resemble true Hamman-Rich syndrome with the purpose to underline that the syndrome is an acute idiopathic interstitial lung disease, that differs from interstitial subacute and chronic lung diseases based on pathohistological and clinical findings [7;8].

The aetiology, pathogenesis, and factors leading to progressive pneumofibrosis in this syndrome are still unknown. There is a hypothesis that assumes the cascade of events ending up with diffuse alveolar damage that begins with acute lesion and subsequently affects endothelial vascular cells as well as alveolar epithelium. Epithelial cell damage generates local inflammation and systemic acute phase response, when alveolar macrophages produce cytokines similar to tumor necrosis factor-alpha, interleukin- 1 beta and chemotactic factor of monocytes - all intensifying inflammatory response. In the alveoli degenerating epithelial cells form hyaline membranes which subsequently serve as a base for inflammatory cells, fibroblasts, and myofibroblasts promoting fibroplasia. This phase is characterized by fibroblasts proliferation, connective tissue generation, the process occurs within the interstitial space and generates its expansion and decrease of gas diffusion.

It is also important to mention that acute interstitial pneumonia is not limited to cases that show only organized diffuse alveolar damage, because acute phase and organized tissue damage can coexist in the same biopsy. Inflammatory cells, especially neutrophils, are very few in majority of cases with no reveal of microorganisms. Diffuse proliferation of the fibroblasts distinguishes acute interstitial pneumonia from usual interstitial pneumonia, entity where fibrosis is chronologically older with small isles of fibroblasts only [9].

The Hamman-Rich syndrome is characterized by rapid progression from symptoms of common cold such as cough (usually non-productive, sometimes with scanty sputum), fever, chills and dyspnea, aggravating to disorder of $\mathrm{pO}_{2}$ and $\mathrm{pCO}_{2}$ in blood and severe respiratory failure. The rapid progressing of respiratory failure is related to non-ventilatory (aka: "parenchymal") mechanism of decreased diffusion across alveoli-capillary barrier and altered perfusion of microcirculatory bed in lesser circulation. This acute syndrome affects apparently healthy individuals and is not associated with prior chronic lung diseases, smoking habits, age or gender [10]. At the same time the progression of the disease is not associated with comorbid background such as bronchial asthma and can affect people most often aged over 40, with a most typical age of 50-55 [11-13], although adolescent and pediatric cases were also described [14-21].

\section{Aetiology: Genes and environmental factors mosaic interplay}

Since Hamman-Rich syndrome occurs both in children and in adults, and there were a lot of familial cases described in populations of various ethnicity, it is considered to have a hereditary background, and there is an assumption that the syndrome is a genetic disease. It was presumed that Hamman-Rich syndrome is an illness with autosomal dominant inheritance type [14-20]. 
But the genetic aspects of its aetiology are still far from complete elucidation. Familial cases of the disease resembling this syndrome were described previously in few articles in several generations of relatives. But it is not clear if any of them could match the current definition of Hamman-Rich syndrome as an acute interstitial pneumonia. Most probably there is a group of hereditary disorders related to surfactant proteins and their metabolism more or less resembling classical manifestations of Hamman-Rich syndrome, but not representing a single entity.

Several descriptions of interstitial pneumoniae and interstitial pneumofibrosis in children and adults, first in twin sisters [22] and later in several members of the same family in few generations with acute of subacute manifestations were published. In early publications their disorders were interpreted as cases of Hamman-Rich syndrome or familial fibrocystic pulmonary displasia, or fibrosing interstitial pneumonitis [23-25]. Generally speaking, the pedigrees witnessed for autosomic dominant trait with incomplete penetrance. Retrospective molecular genetic analysis of their biomaterial was performed in 2002 by Thomas A. Q. et al. [26]. As a result, they found a heterozygous T-to-A transversion at genomic position exon $5+128$ in the SFTPC gene in chromosome $8 \mathrm{p}$, encoding highly hydrophobic surfactant $\mathrm{C}$ protein (SP-C), produced via several proteolytic precursor steps, exclusively by type II alveolocytes. The mutation results in a leu188-to-gln (L188Q) substitution in a highly conserved region of the C-terminal domain. This region is crucial to proper intracellular trafficking/folding of the protein. The phenotype in this family was variable, with adults showing signs of usual interstitial pneumonitis and children showing signs of cellular nonspecific interstitial pneumonitis. Immunostaining showed aberrant subcellular localization of the SP-C precursor protein with probable disorder of its transportation [26].

Thus, surfactant system function establishing the low oxygen costs of breath and preventing alveoli from collapse on exhale by surface tension decrease could be jeopardized in these patients. The mutations of SP-C are most frequent ones predisposing to interstitial lung diseases in children, but they may have late manifestation as well. For alveolar epithelium these mutations may result in a cell toxicity, increased endoplasmic reticulum stress, inflammation and enhanced apoptosis. The distorted epithelial-mesenchymal transition under the influence of paracrine inflammatory autacoids causes later diffuse interstitial fibrosis of lungs [27].

The remarkable feature of the data on probable genetic origin of Hamman-Rich syndrome and all closely related entities, resembling its clinical and pathomorphological picture, is the presence of different pathological findings in individuals sharing the same mutations. This can witness for pleiotropic manifestations of the same core link(s) of pathogenesis. Also, in various cases of disease penetrance of genetic defect depended on age (more acute and even fulminant in younger individuals) and on various external provoking factors - influenza and other infections, occupational hazards etc. The pathomorphological data also are age-depending. Nathan N. et al. emphasized that: "ground glass opacities intensity and extension were decreasing over time, whereas septal thickening, subpleural and intraparenchymal cysts, and even honeycombing were appearing and increasing with age" [28]. It looks like non-genetic events can render lifelong influence on penetrance of genetic defects related to Hamman-Rich-like disorders.

There have been described cases of acute and subacute interstitial lung disease in infants and adults with the pathogenesis mainly connected to molecular targets, other 
than SP-C. It may be gene, encoding ATP-binding cassette-family A-member 3, which is responsible for transportation of surfactant proteins $\mathrm{B}$ and $\mathrm{C}$ into lamellar bodies (ABCA3 in chromosome 16, recessive trait); or the NKX homeobox 2 gene, which encodes transcriptional promoter of surfactant proteins $\mathrm{C}$ and $\mathrm{A}$ as well as $\mathrm{ABCA} 3$ in lung and some other organs (NKX2-1 in chromosome 14, with dominant trait, responsible for lungthyroid-diencephalon syndrome); or finally genes of other surfactant proteins - A (in chromosome 10) and B (in chromosome 2, recessive trait).

Surfactant protein B deficiency which caused fatal respiratory failure in a full-term infant was described in 1993 for the first time. Following that a lot of cases of the immediate respiratory failures in newborns were published, and most of them had fatal evolution despite aggressive management. Surfactant protein A defects are mostly manifested in adults.

Pathogenesis of all aforementioned genocopies of surfactant system disorders involves lung primary parenchymal dysfunctions and acute respiratory distress syndrome. Among the provoking events there are occupational/environment insults, drugs, radiation exposure, rheumatological autoimmune diseases, vasculitides, auto-inflammatory disorders and viral infections [27; 29].

We consider that Hamman-Rich syndrome, at least, is not induced by the bacterial aetiological factors, because there is no effect from antibacterial therapy [19], and blood concentrations of biomarkers such as MMP-7, CCL18, KL-6, SP-A и SP-D are significally different in cases of bacterial pneumoniae and Hamman-Rich syndrome [29].

Viruses took one of the central roles in mechanism of pediatric interstitial lung diseases, as they target alveolar epithelium. Hence, viral provocation considered to be essential for Hamman-Rich syndrome. Among viral agents most often mentioned in relation to Hamman-Rich syndrome are: Adenovirus, Epstein-Barr virus, cytomegalovirus, and respiratory syncytial virus. More rarely implicated are: Influenza A, hepatitis $\mathrm{C}$ and human immunodeficiency virus [30-32].

\section{Pathogenesis and manifestations of Hamman-Rich syndrome}

The pathogenesis of the Hamman-Rich syndrome is obscure. The following possible players in mechanisms underlying this fulminant lung disease are: Natural killer cells and excessive action of certain type of cytokines - so-called cytokine storm (especially, mediated via interleukin-18 and interleukin-2). These agents can play the leading part in the pathogenesis of the acute cell injury with the resulting no remitting fibrosis, in particular through cell injury [31-33]. Other authors suppose that immune complexes play some role in pathogenesis as they are commonly involved in many cases of vasculitides [34]. The role of autoimmune component in Hamman-Rich syndrome pathogenesis is not rejected, because many of the viruses mentioned above as its triggers, are also known to provoke autoimmunity (like Epstein-Barr virus, citomegalovirus, and hepatitis $C$ virus [29].

The disease is often preceded by acute upper respiratory tract infection that lasts approximately 1-2 weeks. The most common symptoms are dyspnea, cough, sub febrile temperature and in some cases - high fever. Patients can also suffer from muscle weakness and fibromyalgia. Acute respiratory failure develops in previously healthy patients without any chronic lung diseases. The symptoms of acute respiratory failure include tachypnea, dyspnea, cyanosis, whistles and wheezing of the lungs on auscultation. Fulmi- 
nant respiratory failure usually affects patients between 50-55 years old equally males and females without prior risk factors in anamnesis [35].

The above mentioned initial clinical symptoms of the acute interstitial pneumonitis are caused by acute phase response with prodromal/catarrhal symptoms that progress very fast (in several days) to bilateral pneumonia and respiratory insufficiency leading to fatal outcome almost in $70 \%$ of cases.

Basically, the patient is feeling like he or she is drowning - previously healthy individual without chronic respiratory disease can develop fulminant respiratory insufficiency after the initial symptoms of common cold.

Final diagnosis is made based on clinical picture and histopathological studies of the patients with acute respiratory failure. In the early stages of diffuse alveolar damage hyaline membranes are determined. As the disease progresses, resorption of hyaline membranes occurs, fibroblasts migrate to alveolar septation area and rapidly proliferate, causing elevated Ki67 marker expression on immunohistochemistry. In the late stages interstitial fibroblasts consolidation is observed. Characteristic features can include atelectasis, hyperplasia of pneumocytes type 2, edema of interalveolar septum, and micro- thrombosis of small pulmonary arteries. Cytology can be described as alveolar macrophages and scattered mixed inflammatory cells. Diagnosis is proved by computed tomography of high resolution. The main findings of instrumental research methods are bilateral symmetric pulmonary infiltration that can be local or diffuse. Spirometry shows restrictive pattern with decreased diffusing capacity of the lungs. Laboratory tests are characterized by neutropenic leukocytosis, increased creatinine, decreased hematocrit, that is considered a bad prognostic factor. Bronchoalveolar lavage usually shows neutrophilia with accidental atypical pneumocytes type 2 and extracellular amorphous material that represents fragments of hyaline membranes. Lavage study is used to differentiate acute respiratory pneumonia from other types of pneumonia. So, for example, absence of eosinophils can help to exclude acute eosinophilic pneumonia, absence of lymphocytosis and foam macrophages may exclude cryptogenic pneumonia, and pneumonia caused by medications. Biopsy helps to exclude known causes of diffuse alveolocytes' damage, for instance, such as idiopathic lung fibrosis exacerbation [11].

Chest X-ray shows diffuse bilateral lung tissue air opacification that resembles ground glass or smoke. High resolution computed tomography (CT) scan of the chest shows bilateral symmetrical patches that resemble hyaline opacities. The acute interstitial pneumonitis resembles other cases of acute respiratory distress syndrome both clinically and instrumentally [36]. The main criteria of the acute respiratory syndrome include: Idiopathic acute respiratory distress and histopathological findings consistent with organized pneumonia.

The diagnosis of Hamman-Rich syndrome is based on 4 principles: 1) acute onset of symptoms which coincide with severe hypoxemia and in majority of cases - respiratory failure; 2) bilateral pulmonary infiltrates evident on radiological images; 3) absence of identified aetiology or predisposing condition; 4) pathohistology report with idiopathic diffuse alveolar damage, finding which is not present in any other idiopathic interstitial pneumonia.

To confirm the diagnosis it is essential to perform open thoracoscopic lung biopsy. The findings of the biopsy during the exudative phase are characterized by edema, hyaline membranes, acute interstitial inflammation, and later, during the organized phase - by 
organized fibrosis, preferably located between alveolar septae with hyperplasia of type 2 pneumocytes [5].

It is worth to note that Hamman-Rich syndrome is regularly complicated by pulmonary heart disease (cor pulmonale) and heart failure [37].

\section{Still without radical treatment}

The treatment of Hamman-Rich syndrome is mostly symptomatic and/or supportive: with oxygen therapy and mechanical lung ventilation. It is not clear whether glucocorticoid therapy is always effective as a treatment method of the acute interstitial pneumonitis. Some specialists came to conclusion that it is necessary to use pulse therapy with maximal doses of corticosteroids as the most effective among other methods of conservative treatment [38]. Other immunosuppressing medicines and anti-fibrotic therapy also is used. Glucocorticoids in pediatric cases of Hamman-Rich syndrome look more effective (circa $50 \%$ of recovery), than in elderly patients, mortality rate in children is lower (circa $15 \%$ ), than in adults $[32 ; 39]$. Interestingly, chloroquine was tested for therapy of Hamman-Rich syndrome and showed $60 \%$ effectiveness [40].

In adults even the aggressive treatment, which includes mechanical lung ventilation, is characterized by a high rate of lethality (more than $60 \%$ ), and most patients die during the next 6 months after initial hospitalization. But, getting the disease once, patients (if they did overcome it) do not get sick again after recuperation and, according to the laboratory and instrumental data, in many cases have considerable recovery of the functional lung capacity [41].

One research specifies higher numbers of survival where the main role is assigned to the early diagnostic approach, protective regimen of lung ventilation and early immunosuppressive therapy usage [5]. One may look many similarities in ways and failures of Hamman-Rich and COVID-19 treatment (see below). There is still an open question regarding target therapy. Potentially, as a candidate for pathogenetic treatment of HammanRich syndrome can be regarded anti-cytokine immunobiotherapy (like in COVID-19).

Some cases of Hamman-Rich syndrome in elderly patients are described in medical literature as a fulminant form of the interstitial lung disease. Prodromal phenomena precede those cases, and in some occasions, there was no response to intensive and even aggressive therapy, including antibacterial therapy, diuretics, glucocorticosteroids, and mechanical lung ventilation. Such cases were often fatal in 10-35 days after hospitalization [42].

Some authors, stressing the importance of open thoracoscopic lung biopsy in diagnosis of Hamman-Rich syndrome, insist on single possible radical approach in its treatment - that is lung transplantation [10].

\section{COVID-19 vs Hamman-Rich syndrome: Close similarities}

The discoverer of general adaptation syndrome, Hungarian-Canadian pathophysiologist Hans Hugo Bruno Selye (1907-1982) once noted, that clinicians always try to find difference between the diseases, but for a pathologist the most interesting thing is why various diseases look so similar.

In regards to Hamman-Rich syndrome, we shall mention a correlation which seems to us quite important. 
Comparing early and advanced clinical manifestations, lung pathomorphology and outcomes, as well as typical sub-acute complications of Hamman-Rich syndrome and features of its treatment - with all that facets of severe COVID-19 [43-45], we noticed strikingly close resemblance of these two entities [37].

The most important facet, in our opinion, is that the pathogenesis of the acute interstitial pneumonitis triggered by COVID-19 with its cytokine cascade and acute respiratory distress, has many similarities to that of Hamman-Rich syndrome. In most severe cases, the course of COVID-19 disease is characterized not only by fever, cough and other constitutional symptoms, but also by acute respiratory insufficiency, dyspnea and possible lethal outcome. Laboratory data will reveal leukopenia, significant liver transaminases (hundreds or even thousands) and huge ferritin level rise. These signs define also hyperferritinemic syndrome - macrophage activation syndrome, catastrophic antiphospholipid syndrome, septic shock and side effects on the biological component anti-CD-28. Such clinical scenario may be universal and can correlate with the syndrome of macrophage activation that is associated with high ferritin levels, wich was first coined by Yehuda Shoenfeld et al. in 2020 [3]. Acute respiratory distress syndrome is the devastating clinical manifestation of COVID-19 pneumonia that is mainly based on immune-mediated pathological processes. Current studies show that pneumonia cascade in any case, not excluding neither old, nor newest aetiologies, is mediated by maladaptive inflammatory responses that excessively activate innate immune responses [32-33]. So called cytokine storm was detected and documented with the participation of IL-6, IL-2, and IL-18 [3; 43-45]. The activation of complement $\mathrm{C}_{3}$ system, as the primary trigger mechanism impairing pulmonary tissue on preclinical models by infection SARS-CoV-2, was described [46].

Indeed, in our opinion the severe COVID-19, with its fever and dry non-productive cough and coming later interstitial pneumonia with diffuse alveolar damage and acute respiratory distress syndrome, as well as with its outcome to diffuse interstitial pneumofibrosis - looks in all above said features - very much like acquired "phenocopy" of Hamman-Rich syndrome, although latter apparently never was considered to be a contagious disease.

Either sporadic cases of Hamman-Rich syndrome were related to unrecognized type of coronavirus having small contagiousness. Or, which looks much more probable, both entities, having different (infectious and non-infectious, presumably, genetic) aetiologies, address in their pathogenesis to similar or identical weak point(s) of immune system, making its auto-inflammatory and auto-aggressive potential the key player in both entities.

Anyway, it seems to us quite possible that Hamman-Rich syndrome under closer look may contain a key for comprehension of the COVID-19. There was even an observation that pneumofibrosis in survivors of Hamman-Rich syndrome can exacerbate into acute respiratory distress syndrome due to viral and even coronavirus infection, although last was reported only in one of 43 cases of such exacerbation [47; 48]. To study precisely and compare the genetic and immunological features of those people having severe COVID-19 and those suffered from Hamman-Rich syndrome may offer a fruitful approach for prognostic purposes and pathogenetically based intervention [37].

Inherited epigenetic dysregulations of the immune system can be the portals of entry for infection, thus contributing to viremia and launching of excessive immune response to SARS-CoV-2 [49] or other still unknown Hamman-Rich syndrome provoking agent(s). 
In regards to probable common targets of pathological processes in both COVID-19 and Hamman-Rich syndrome, one has to think about involvement of the surfactant system.

We already cited a comprehensive international study which demonstrated the existence of autoimmune links in pathogenesis of COVID-19, with lymphoid infiltration of lungs and other organs and provocation of different autoimmune diseases by COVID-19 [3].

But, the Hamman-Rich syndrome also was linked to some autoimmune conditions. Frequent comorbidity of this syndrome and autoimmune rheumatological diseases has been described. Up to $40 \%$ of cases in some samplings were positive for antinuclear autoantibodies or rheumatoid factors [38; 50; 51]. Interstitial fibrosing alveolitis overlapping with manifestations of Hamman-Rich syndrome can be observed in children and adults affected with several autoimmunopathies: Rheumatoid arthritis, systemic sclerosis, systemic lupus erythematosus, Sjögren syndrome, dermatomyositis and polymyositis, ankylosing spondylitis, and mixed connective tissue disease, as well as in autoimmune vasculitides and anti-synthetase syndrome [28; 52]. Some autoantibodies, like anti-Ro52 and anti-Ku correlated with dyspnea and other symptoms in patients with interstitial lung diseases, including acute ones [52].

There is a common general rule in Pathophysiology, that similar disorders may be brought in by either genetic defect of certain protein, or equally - by autoantibodies against this protein, spoiling its function and/or assembly with other proteins, even without its primary genetic defects. This can be illustrated by the examples of similarities between primary inherited or secondary autoimmune cardiomyopathies, or by the case of inherited blistering mechanodermatoses versus acquired immunodermatoses, which clinically closely resemble them $[53 ; 54]$.

We hypothesize, that similar parallelism may exist between Hamman-Rich syndrome and COVID-19.

As it was mentioned above, hereditary defects of surfactant proteins (SP-C and others) and molecules involved in their transportation and metabolism are of utmost significance for the genetic background of Hamman-Rich syndrome and those forms of pathology closely related to it. For example, there are cases of idiopathic pulmonary fibrosis that are caused by heterozygous mutation in the SFTPA2 gene (178642). This gene encodes pulmonary surfactant protein A2 on chromosome 10q22 [55].

D. Kanduc and Y. Shoenfeld suggested recently that because the SARS-CoV-2 spike glycoprotein and lung surfactant proteins shared 13 out of 24 pentapeptides, the immune response following infection with SARS-CoV-2 may lead to cross-reactions with pulmonary surfactant proteins, followed by SARS-CoV-2-associated lung disease. Later A. Vojdani et al have broaden these studies [56; 57].

Human vs SARS-CoV-2 peptide sharing is of high relevance with 13 out of the 24 shared pentapeptides to be found in 52 SARS-CoV-derived immunoreactive epitopes. Given the caveat that the positive correlation of the pentapeptide sharing needs to be controlled by serologic validation, results suggest that immune responses following SARSCoV-2 infection might lead to cross reactions with pulmonary surfactant and related proteins, and might contribute to the SARS-CoV-2-associated lung diseases [56].

Looking at the reaction between SARS-CoV-2 spike protein antibody and other tissue proteins the strongest reactions were found with transglutaminase 3 (tTG3), transglutaminase 2 (tTG2), ENA, myelin basic protein (MBP), mitochondria, nuclear antigen (NA), $\alpha$ - myosin, thyroid peroxidase (TPO), collagen, claudin 5+6, and S100B [57]. 
There is a possibility that SARS-CoV-2 infection through autoantibodies induction may damages the same peptides of surfactant proteins that are defective in a hereditary form of idiopathic fibrosing alveolitis cases close to Hamman-Rich syndrome.

There are many similarities in ways of treatment for Hamman-Rich syndrome (see above) and severe COVID-19 because acute respiratory distress syndrome occurs in both diseases. Exactly like in Hamman-Rich syndrome, in COVID-19 also there are reports of successful use of corticosteroids, but despite intensive treatment with glucocorticosteroids the lethal cases are not rare [58]. The alternative immunosuppressive medications (chloroquine, vincristine, cyclophosphamide, cyclosporin, and azathioprine) and lung transplantation have also been presented in some pilot projects as possible treatment methods, although with limited efficacy [59].

\section{Hamman-Rich syndrome and COVID-19: Hard differential diagnosis}

The similarity between Hamman-Rich syndrome and COVID-19 is not only just theoretical consideration coined by pathologists. It already created some practical hardships in differential diagnosis during current COVID-19 pandemic.

Thus, Jennifer Obasi describes a case of previously healthy 64 years old female who presented with symptoms of acute dyspnea, fever, unproductive cough, arthralgias and myalgias and despite aggressive treatment with high-dose corticosteroids, mechanical ventilation, continued to experience refractory hypoxia and subsequently passed away. She was COVID-19 negative, did not have any chronic lung disease. The patients autopsy confirmed findings characteristic for diffuse alveolar damage: interstitial edema with alveolar septae thickening, inflammatory cell infiltration, hyaline membranes alongside of the alveolar septa in focal areas and thrombi in small pulmonary arteries. A diagnosis of acute interstitial pneumonia (Hamman-Rich syndrome) was made [60].

The differential diagnosis between Hamman-Rich syndrome and acute interstitial pneumonia triggered by COVID-19 is challenging because the clinical presentation is similar - prodromal illness lasts 7-14 days prior to rapid onset of respiratory failure, fever, nonproductive cough, fatigue. Radiological findings are the same: patients with confirmed COVID-19 had extensive ground-glass opacities on CT-scans, as well as patients with negative COVID-19 tests and acute interstitial pneumonias. Atypical presentation of COVID-19 disease can also be taken into consideration while interpreting clinical and radiological findings. A case of differential diagnosis between COVID-19 and HammanRich syndrome in a 77 years old female Chinese patient was reported just recently [61]. The bronchoscopy with lung biopsy can be useful while making a diagnosis of HammanRich syndrome. An interesting case of incidental tracheal bronchus found during bronchoscopy in a patient with Hamman-Rich syndrome was described by Luca Conti [62]. The role of bronchoscopy is to eliminate other possible diagnoses such as alveolar hemorrhage, eosinophilic infiltrates, or lymphoma / cancer infiltrates. Bronchoalveolar lavage can show in Hamman-Rich syndrome presence of neutrophils, atypical epithelial cells, however those findings are not specific, that is why open or video guided lung biopsy can be beneficial [9]. Alongside acute respiratory distress syndrome, there are 3 types of interstitial pneumoniae that should be excluded: Usual interstitial pneumonia, desquamous interstitial pneumonia and cryptogenic organized pneumonia. The main difference is based on disease duration. Acute interstitial pneumonia (equivalent of classic Hamman-Rich 
syndrome) takes its fulminant course, whereas desquamous pneumonia, in addition to tobacco smoking association, has subacute course of weeks and months, and usual pneumonia lasts during years. Cryptogenic pneumonias, although acute, respond excellently to systemic corticosteroid treatment and have excellent clinical prognosis.

\section{Conclusion}

History of Pathology is not just a dead dusty book from a remote shelf of rarely visited library store. Sometimes it may teach contemporary physicians helping to comprehend diseases which seem to be new, and in these cases a disease "out of fashion" gives much for better understanding of a "disease in fashion". The incidence and epidemiological dynamics of COVID-19 is followed daily by everyone, even those observers standing beyond professional medical community. But the epidemiology of Hamman-Rich syndrome and related idiopatic fibrosing interstitial lung diseases for a long time was out of scope of scholarly attention. We were able to retrieve only one such study of mid-1990ies, documenting the increase in its mortality rate, especially in Britain, as well as the prevail of male patients in all countries studied [63].

But, an old discovery by L. V.Hamman and L. R. Rich [64-66] definitely has a big chance to come in fashion again with the progress of COVID-19 pandemic.

\section{Authors' contribution}

Leonid Churilov - idea, analysis of literature, final edition; Yana Ivashkevich - collection of foreign literature, draft version; Alexander Korovin - analysis of literature; Alina Petryaeva - analysis of domestic literature, technical assistance.

\section{References}

1. Yuki K., Fujiogi M., Koutsogiannaki S. COVID-19 pathophysiology: A review. Clin Immunol. 2020, vol. 215, 108427. https://doi.org/10.1016/j.clim.2020.108427.

2. Zhou G., Chen S., Chen Z. Advances in COVID-19: the virus, the pathogenesis, and evidence-based control and therapeutic strategies. Front Med.2020, vol. 14, no. 2, pp. 117-125. https://doi.org/10.1007/ s11684-020-0773-x.

3. Ehrenfeld M., Tincani A., Andreoli L., Cattalini M., Greenbaum A., Kanduc D., Alijotas-Reig J., Zinserling V., Semenova N., Amital H., Shoenfeld Y. COVID-19 and autoimmunity. Autoimmun Rev. 2020, vol. 19, no. 8, 102597. https://doi.org/10.1016/j.autrev.2020.10259.

4. Mrad A., Huda N. Acute Interstitial Pneumonia. 2020 Aug 11. StatPearls [Internet]. Treasure Island (FL), StatPearls Publishing; 2020. Jan-. PMID: 32119316.

5. Mastan A., Murugesu N., Hasnain A., O’Shaughnessy T., Macavei V. Hamman-Rich syndrome. Respir Med Case Rep. 2017, vol. 23, pp. 13-17. https://doi.org/10.1016/j.rmcr.2017.10.008.

6. Zhang W., Zhao Y., Zhang F., Wang Q., Li T., Liu Z., Wang J., Qin Y., Zhang X., Yan X., Zeng X., Zhang S. The use of anti-inflammatory drugs in the treatment of people with severe coronavirus disease 2019 (COVID-19): The Perspectives of clinical immunologists from China. Clin Immunol., 2020, vol. 214, 108393. https://doi.org/10.1016/j.clim.2020.108393.

7. Katzenstein A.L., Myers J.L., Mazur M.T. Acute interstitial pneumonia. A clinicopathologic, ultrastructural, and cell kinetic study. Am J Surg Pathol., 1986, vol. 10, no. 4, pp. 256-267.

8. Katzenstein A.L., Myers J.L., Prophet W.D., Corley L.S. $3^{\text {rd }}$, Shin M.S. Bronchiolitis obliterans and usual interstitial pneumonia. A comparative clinicopathologic study. Am J Surg Pathol., 1986, vol. 10, no. 6, pp. 373-381. https://doi.org/10.1097/00000478-198606000-00002.

9. Severiche Bueno D. F., Vargas Cuervo M. T., Severiche Hernández D. L., Cerchiaro D. M., Hernandez H.S., Benigni E. M., Severiche Bueno D. F. Neumonía intersticial aguda o síndrome de Hamman- 
Rich. Reporte de un caso. Acta Colombiana de Cuidado Intensivo, 2018, vol. 18, no. 4, pp. 255-260. https://doi.org/10.1016/j.acci.2018.06.004.

10. Newmarch W., Puopolo A., Weiler M., Casserly B. Hamman-Rich syndrome: a forgotten entity. Monaldi Arch Chest Dis. 2017, vol. 87, no. 1, 799 p. https://doi.org/10.4081/monaldi.2017.799.

11. Mukhopadhyay S., Parambil J. G. Acute interstitial pneumonia (AIP): relationship to Hamman-Rich syndrome, diffuse alveolar damage (DAD), and acute respiratory distress syndrome (ARDS). Semin Respir Crit Care Med., 2012, vol. 33, no. 5, pp. 476-485. https://doi.org/10.1055/s-0032-1325158.

12. Vieira F. V., Custódio F. B., Meneses A.C.O. Pneumonia intersticial aguda (síndrome de HammanRich): relato de caso e revisão de literatura. Rev Soc Bras Clin Med., 2016, vol. 14, no. 1, pp. 45-47.

13. Lemle A., Pubens J., Vieira L. O. Fibrose pulmonar difusa idiopática - possível síndrome de HammanRich. Apresentação de um caso com exploração funcional pulmonar. Rev Bras Med., 1968, vol. 25, no. 2, pp. 85-91.

14. Thomas H., Costabel U. Progredient verlaufende idiopathische Lungenfibrose bei zwei eineiigen Zwillingsschwestern. Pneumologie, 1996, vol. 50, no. 9, pp. 679-682.

15. Appelman A.C., Buytendijk H. J. Chronische interstitiële longontsteking (Hamman-Rich syndroom) in een gezin. Ned Tijdschr Geneeskd., 1961, vol. 105, pp. 1928-1930.

16. Bariş I., Atrvinli M., Ozesmi M. Familyal Hamman-Rich sendromu. Turk Tip Dernegi Derg., 1973, vol. 39, no. 9, pp. 330-337.

17. Touloukian J.S. A familial variant of the Hamman-Rich syndrome. J Indiana State Med Assoc., 1975, vol. 68, no. 11, pp. 956-958.

18. Vogel C., Scheibe F. W. Zur frage des Hamman-Rich-syndroms im kindesalter (diffuse und nodulaere lungengeruesterkrankung bei 2 geschwistern). Kinderarztliche Praxis., 1963, vol. 31, pp. 285-292.

19. Gabitova N. K., Cherezova I. N., Cherezova K. A. Idiopatic fibrosing alveolitis in a newborn. Rossiiskii Vestnik Perinatologii i Pediatrii, 2019, vol. 64, no. 5, pp. 226-229. (In Russian)

20. Zinchenko R.A., Murzabaeva S.Sh., Grinberg Ya. I., Galkina V.A., Bessonova L.A., Dadali E.L., Khlebnikova O. V., Khidiyatova I. M., Grinberg E. R., Fedotov V.P., Elchinova G. I., Shchagina O.A., Polyakov A. V., Khusnutdinova E. K., Ginter E. K. Medical genetic study of the population of the Republic of Bashkortostan. Proceeding IX. Factors of population dynamics that determine the values of the burden of monogenic hereditary diseases. Med. Genetics, 2009, vol. 8, no. 5, pp. 11-23. (In Russian)

21. Mizernitsky Y.L., Rozinova N. N., Sokolova L. V., Bogorad A.E., Gryazina O. V. Rare lung diseases in children - an actual pulmonology problem. Rossiiskii Vestnik Perinatologii i Pediatrii, 2012, vol. 57, no. 4-1, pp. 44-49. (In Russian)

22. Peabody J. W., Peabody J. W. Jr., Hayes E. W., Hayes E. W. Jr. Idiopathic pulmonary fibrosis; its occurrence in identical twin sisters. Dis Chest., 1950, vol. 18, no. 4, pp. 330-344. https://doi.org/10.1016/ s0096-0217(15)34710-5.

23. Donohue W. L., Laski B., Uchida I. A., Munn J. D. Familial fibrocystic pulmonary dysplasia and its relation to the Hamman-Rich syndrome. Pediatrics, 1959, vol. 24, pp. 786-813.

24. Young W. A. Familial fibrocystic pulmonary dysplasia: a new case in a known affected family. Canad. Med. Assoc. J., 1966, vol. 94, pp. 1059-1061.

25. Swaye P., Van Ordstrand H.S., McCormack L.J., Wolpaw S.E. Familial Hamman-Rich syndrome. Report of eight cases. Dis Chest., 1969, vol. 55, no. 1, pp. 7-12. https://doi.org/10.1378/chest.55.1.7.

26. Thomas A. Q., Lane K., Phillips J.3 ${ }^{\text {rd }}$, Prince M., Markin C., Speer M., Schwartz D. A., Gaddipati R., Marney A., Johnson J., Roberts R., Haines J., Stahlman M., Loyd J.E. Heterozygosity for a surfactant protein $\mathrm{C}$ gene mutation associated with usual interstitial pneumonitis and cellular nonspecific interstitial pneumonitis in one kindred. Am J Respir Crit Care Med., 2002, vol. 165, no. 9, pp. 1322-1328. https://doi.org/10.1164/rccm.200112-123OC.

27. Nathan N., Berdah L., Delestrain C., Sileo C., Clement A. Interstitial lung diseases in children. Presse Med., 2020, vol. 49, no. 2, 103909. https://doi.org/10.1016/j.lpm.2019.06.007.

28. Nathan N., Sileo C., Thouvenin G., Berdah L., Delestrain C., Manali E., Papiris S., Léger P.L., Pointe H. D. L., l'Hermine A. C., Clement A. Pulmonary Fibrosis in Children. J Clin Med., 2019, vol. 8, no. 9, 1312. https://doi.org/10.3390/jcm8091312.

29. Nathan N., Berdah L., Borensztajn K., Clement A. Chronic interstitial lung diseases in children: diagnosis approaches. Expert Rev Respir Med., 2018, vol. 12, no. 12, pp. 1051-1060. https://doi.org/10.108 $0 / 17476348.2018 .1538795$.

30. Leshchenko I. V., Zherebtsov A. D. Idiopathic pulmonary fibrosis: modern view of pathogenesis and the role of biomarkers. RMJ, 2018, vol. 10, no. 1, pp. 6-10. (In Russian)

31. Clement A., de Blic J., Epaud R., Galeron L., Nathan N., Hadchouel A., Barbato A., Snijders D., Kiper N., Cunningham S., Griese M., Bush A., Schwerk N. Management of children with interstitial lung 
diseases: the difficult issue of acute exacerbations. Eur Respir J., 2016, vol. 48, no. 6, pp. 1559-1563. https://doi.org/10.1183/13993003.01900-2016.

32. Clement A., Nathan N., Epaud R., Fauroux B., Corvol H. Interstitial lung diseases in children. Orphanet J Rare Dis., 2010, vol. 5, p. 22. https://doi.org/10.1186/1750-1172-5-22.

33. Plasek J., Dvoračkova J., Jahoda J., Trulikova K., Mokosova R., Danek T., Hrabovsky V., Martinek A. Acute interstitial pneumonia (Hamman-Rich syndrome) in idiopathic pulmonary fibrosis and bronchoalveolar carcinoma: a case report. Biomed Pap Med Fac Univ Palacky (Olomouc Czech Repub), 2011, vol. 155, no. 4, pp. 403-407. https://doi.org/10.5507/bp.2011.039.

34. Minenkova T. A., Mizernitskiy Yu. L., Razinkova N. S., Serezhkina A. V., Kostyuchenko M. V. Hamman-Rich syndrome in a young child. Rossiiskii Vestnik Perinatologii i Pediatrii, 2019, vol. 64, no. 4, pp. 83-87. (In Russian)

35. Chertoff J., Alnuaimat H. A 45-Year-Old Woman with Acute Interstitial Pneumonia (HammanRich Syndrome). Turk J Anaesthesiol Reanim., 2017, vol. 45, no. 4, p.244. https://doi.org/10.5152/ TJAR.2017.98105.

36. Fujita J., Tohyama M., Haranaga S., Cash H. L., Higa F., Tateyama M. Hamman-Rich syndrome revisited: how to avoid misdiagnosis. Influenza Other Respir Viruses, 2013, vol. 7, no. 1, pp. 4-5. https://doi. org/10.1111/j.1750-2659.2012.00353.x.

37. Stroev Y.I., Churilov L.P. Diagnosis of the Diseases of Respiratory System and Its Pathophysiological Basis: III. Cor Pulmonale - Pulmonary Heart Disease. Russian Biomedical Research, 2020, vol. 5, no. 2, pp. 4-16.

38. Feshhenko Ju. I., Gavrisjuk V.K., Monogarova N.E., Jachnik A.I. Idiopathic fibrosing alveolitis as a form of idiopathic interstital pneumonia. Ukraïns'kii pul'monologichnii zhurnal, 2004, vol. 4, pp. 5-11. (In Russian)

39. Hewitt C. J., Hull D., Keeling J. W. Fibrosing alveolitis in infancy and childhood. Arch Dis Child., 1977, vol. 52, no. 1, pp. 22-37. https://doi.org/10.1136/adc.52.1.22.

40. Sharief N., Crawford O. F., Dinwiddie R. Fibrosing alveolitis and desquamative interstitial pneumonitis. Pediatr Pulmonol., 1994, vol. 17, no. 6, pp. 359-365. https://doi.org/10.1002/ppul.1950170604.

41. Bruminhent J., Yassir S., Pippim J. Acute interstitial pneumonia (Hamman-Rich syndrome) as a cause of idiopathic acute respiratory distress syndrome. Case Rep Med., 2011, vol. 2011, 628743. https://doi. org/10.1155/2011/628743.

42. Avnon L. S., Pikovsky O., Sion-Vardy N., Almog Y. Acute interstitial pneumonia-Hamman-Rich syndrome: clinical characteristics and diagnostic and therapeutic considerations. Anesth Analg., 2009, vol. 108, no. 1, pp. 232-237. https://doi.org/10.1213/ane.0b013e318188af7a.

43. Hamid S., Mir M. Y., Rohela G. K. Novel coronavirus disease (COVID-19): a pandemic (epidemiology, pathogenesis and potential therapeutics). New Microbes New Infect., 2020, vol. 35, 100679. https://doi. org/10.1016/j.nmni.2020.100679.

44. Harapan H., Itoh N., Yufika A., Winardi W., Keam S., Te H., Megawati D., Hayati Z., Wagner A.L., Mudatsir M. Coronavirus disease 2019 (COVID-19): A literature review. J Infect Public Health, 2020, vol. 13, no. 5, pp. 667-673. https://doi.org/10.1016/j.jiph.2020.03.019.

45. Ye Q., Wang B., Mao J. The pathogenesis and treatment of the 'Cytokine Storm' in COVID-19. J Infect., 2020, vol. 80, no. 6, pp. 607-613. https://doi.org/10.1016/j.jinf.2020.03.037.

46. Mastaglio S., Ruggeri A., Risitano A.M., Angelillo P., Yancopoulou D., Mastellos D. C., HuberLang M., Piemontese S., Assanelli A., Garlanda C., Lambris J. D., Ciceri F. The first case of COVID-19 treated with the complement C3 inhibitor AMY-101. Clin Immunol., 2020, vol. 215, 108450. https:// doi.org/10.1016/j.clim.2020.108450.

47. Wootton S.C., Kim D. S., Kondoh Y., Chen E., Lee J.S., Song J. W., Huh J. W., Taniguchi H., Chiu C., Boushey H., Lancaster L.H., Wolters P. J., DeRisi J., Ganem D., Collard H. R. Viral infection in acute exacerbation of idiopathic pulmonary fibrosis. Am J Respir Crit Care Med., 2011, vol. 183, no. 12, pp. 1698-1702. https://doi.org/10.1164/rccm.201010-1752OC.

48. Azadeh N., Limper A. H., Carmona E. M., Ryu J.H. The Role of Infection in Interstitial Lung Diseases: A Review. Chest, 2017, vol. 152, no. 4, pp. 842-852.

49. Sawalha A.H., Zhao M., Coit P., Lu Q. Epigenetic dysregulation of ACE2 and interferon-regulated genes might suggest increased COVID-19 susceptibility and severity in lupus patients. Clin Immunol., 2020, vol. 215, 108410. https://doi.org/10.1016/j.clim.2020.108410.

50. Rautenstrauch H. Diffuse interstitielle Lungenfibrose (Hamman-Rich-Syndrom) und primär chronische Polyarthritis. Z Gesamte Inn Med., 1971, vol. 26, no. 1, pp. 39-41. 
51. Pratt D.S., Schwartz M.I., May J.J., Dreisin R.B. Rapidly fatal pulmonary fibrosis: the accelerated variant of interstitial pneumonitis. Thorax, 1979, vol. 34, no. 5, pp. 587-593. https://doi.org/10.1136/ thx.34.5.5874.

52. Vojinovic T., Cavazzana I., Ceruti P., Fredi M., Modina D., Berlendis M., Franceschini F. Predictive Features and Clinical Presentation of Interstitial Lung Disease in Inflammatory Myositis. Clin Rev Allergy Immunol., 2020. November $3^{\text {rd }}$ [E-pub ahead of print]. https://doi.org/10.1007/s12016-02008814-5.

53. Ryabkova V.A., Shubik Y. V., Erman M. V., Churilov L. P., Kanduc D., Shoenfeld Y. Lethal immunoglobulins: Autoantibodies and sudden cardiac death. Autoimmun Rev., 2019, Apr. 18, vol. 4, pp. 415425. https://doi.org/10.1016/j.autrev.2018.12.005.

54. Fassihi H., Wong T., Wessagowit V., McGrath J. A., Mellerio J.E. Target proteins in inherited and acquired blistering skin disorders. Clin Exp Dermatol., 2006, vol. 31, no. 2, pp. 252-259. https://doi. org/10.1111/j.1365-2230.2006.02065.x.

55. McKusik V.A., Kniffin C.L. OMIM ${ }^{\star} 178620$. Surfactant, Pulmonary Associated Protein C, SFTPC. Available at: https://www.omim.org/entry/ 178620\#22 (accessed: 03.11.2020).

56. Kanduc D., Shoenfeld Y. On the molecular determinants of the SARS-CoV-2 attack. Clin Immunol., 2020, vol. 215, 108426. https://doi.org/10.1016/j.clim.2020.108426.

57. Vojdani A., Kharrazian D. Potential antigenic cross-reactivity between SARS-CoV-2 and human tissue with a possible link to an increase in autoimmune diseases. Clin Immunol., 2020, vol. 217, 108480. https://doi.org/10.1016/j.clim.2020.108480.

58. Han Y., Jiang M., Xia D., He L., Lv X., Liao X., Meng J. COVID-19 in a patient with long-term use of glucocorticoids: A study of a familial cluster. Clin Immunol., 2020, vol. 214, 108413. https://doi. org/10.1016/j.clim.2020.108413.

59. Felsenstein S., Herbert J. A., McNamara P. S., Hedrich C. M. COVID-19: Immunology and treatment options. Clin Immunol., 2020, vol. 215, 108448. https://doi.org/10.1016/j.clim.2020.108448.

60. Obasi J. An Elusive Case of Acute Interstitial Pneumonia. Cureus., 2019, vol. 11, no. 5, e4685. https:// doi.org/10.7759/cureus.4685.

61. Zhang Q., Raza A., Chan V., Minalyan A., Madara J. Hamman-Rich Syndrome: A Diagnosis of Exclusion in the COVID-19 Pandemic. Cureus, 2020, vol. 12, no. 8, e9866. https://doi.org/10.7759/cureus.9866.

62. Conti L., Zammit C. Incidental tracheal bronchus in a case of Hamman-Rich syndrome. BMJ Case Rep., 2019, vol. 12, no. 5, e229579. https://doi.org/10.1136/bcr-2019-229579.

63. Hubbard R., Johnston I., Coultas D. B., Britton J. Mortality rates from cryptogenic fibrosing alveolitis in seven countries. Thorax., 1996, vol. 51 (7), pp. 711-716. https://doi.org/10.1136/thx.51.7.711.

64. Hamman L., Rich A. R. A clinical-pathological conference. A case of heart failure. International Clinics, $43^{\text {rd }}$ series, 1933, vol. 1, pp. 197-232.

65. Hamman L., Rich A. R. Fulminating Diffuse Interstitial Fibrosis of the Lungs. Trans Am Clin Climatol Assoc., 1935, vol. 51, pp. 154-163.

66. Hamman L., Rich A.R. Acute diffuse interstitial fibrosis of the lungs. Bulletin of the Johns Hopkins Hospital, (Baltimore), 1944, vol. 74, pp. 177-212.

\section{Authors' information:}

Yana V.Ivashkevich - MD, Trainee; ivashkevichspb@gmail.com Alexander E.Korovin - D. Sci. (Medicine), Associate Professor; korsyrik@mail.ru Alina V.Petyaeva - MD Student; squirrel.alina@gmail.com

Leonid P. Churilov - MD, PhD, Full Member of International Academy of Sciences (Health and Ecology), Associate Professor; l.churilov@spbu.ru 